\title{
Hematopoietic Cell Transplantation
}

National Cancer Institute

\section{Source}

National Cancer Institute. Hematopoietic Cell Transplantation. NCI Thesaurus. Code C15431.

A therapeutic procedure that involves the transplantation of hematopoietic stem cells, either with the patient as their own donor or from a donor to a patient. This can be used for treatment of malignant and non-malignant diseases. 